\title{
ZNAČILNOSTI POSTMODERNE TER VPLIV VIRTUALNOSTI NA KULTURNI TURIZEM IN IZOBRAŽEVANJE ODRASLIH
}

\section{POVZETEK}

Avtorica proučuje povezave med značilnostmi postmoderne, virtualnostjo novih tehnologij in kulturnim turizmom. Najprej opredeli kulturni turizem ter predstavi njegove sestavine in področja. Obravnava tudi izobraževanje odraslih, tako kulturnih turistov kot prebivalcev v kraju, zlasti izobraževanje za razvoj kulturnega turizma, ki je v postmoderni pomembno gibalo gospodarskega in družbenega razvoja.

Ključne besede: turizem, kulturni turizem, postmoderna, virtualnost, informacijsko-komunikacijske tehnologije, izobraževanje odraslih

\section{CHARACTERISTICS OF POSTMODERNISM AND IMPACTS OF VIRTUALITY ON CULTURAL TOURISM AND ADULT EDUCATION - ABSTRACT}

In her article the author examines the relationship between postmodern phenomena, the virtuality of new technologies and cultural tourism. She starts by defining cultural tourism and proceeds by giving an account of its different elements and domains. Furtheron, she discusses adult education, the education of cultural tourists on the one hand and local inhabitants on the other, the aim of which is to foster cultural tourism as an important agent in the economic and social development of the postmodern society.

Keywords: tourism, cultural tourism, postmodernity, virtuality, information-communication technologies, adult education

$338.48-6: 374.7$

\section{UVOD}

Turizem danes ni več zgolj kulturni turizem, temveč obstaja več vrst turizma: tematski, religiozni, gastronomski, nakupovalni, izobraževalni. Sleherna vrsta turizma ima svoje značilnosti, vendar pa naj bi nas vsaka na ta ali oni način spremenila, prinesla naj bi informacije in novo znanje. Še zlasti to velja za izobraževalni in kulturni turizem. Tako kot na vsa področja človekovega življenja in delovanja in na vsa področja življenja in delovanja skupnosti pa tudi na naravo turizma vplivajo družbene transformacije, razvoj sodobne komunikacijske tehnologije in $\mathrm{v}$ primeru turizma tudi sodobni razvoj transporta. Spremenil se je naš odnos do časa in prostora, spremenili sta se naša identiteta in kultura. Te spremembe neizogibno čutimo tudi v kulturnem turizmu.

\section{OPREDELITEV IN ZNAČILNOSTI KULTURNEGA TURIZMA}

Šele z nastankom kapitalizma in razvojem porabniške družbe se prvič pojavi potreba po prostem času in počitnicah. In tako ljudje takrat začnejo hoditi na počitnice, namesto da bi si kupili ta ali oni predmet. Zaradi želje po doživljanju ugodja in zadovoljstva se uveljavi tudi tako imenovani kulturni turizem
Dr. Vanda Sousa

Faculdade de

Economia e Gestão,

Universidade Lusía-

da de Lisboa 
(Barretto, 2007). To je vrsta turizma, kjer gre za razširjanje splošne razgledanosti, pridobivanje znanja in hkratno željo po čustvenem doživljanju ob odkrivanju kulturne dediščine in krajev, ki se ponašajo s kulturno dediščino (Origet du Clouzeau, 2007).

Poimenovanje kulturni turizem se zdi na prvi pogled pleonazem, saj je bilo v preteklosti sleherno turistično potovanje kulturne narave, namenjeno širjenju duhovnih obzorij, srečanju lastne s tujimi kulturami. Kulturni turisti so bili mladi premožni ljudje, ki so jih prav $\mathrm{v}$ ta namen starši poslali na pot. Kulturni turisti pa so bili tudi pisatelji, ki so na svojih poteh zvesto zapisovali vtise, primerjajoč lastno kulturo s kulturo tujcev, lasten način življenja in razmišljanja $\mathrm{z}$ načinom življenja in razmišljanja drugih. Za ilustracijo navajam primer Michela de Montaigna (pisatelj, filozof, moralist in francoski politik iz časov renesanse, 1533-1592) in njegovega odnosa do potovanja, izpričanega $\mathrm{v}$ delu Potovanje v Italijo prek Švice in Nemčije. To potovanje je trajalo 17 mesecev, Montaigne pa pravi takole: »Potovati se mi zdi vredna dejavnost. Duh je stalno v delovanju, v želji, da zagleda nepoznane in nove reči, in ne morem reči, da poznam kakšno boljšo šolo življenja, kot je potovanje, kjer se nenehno pred očmi riše raznolikost številnih drugih življenj, mnenj in navad.« Kulturni turizem je torej pridobivanje znanja, in to izkustvenega znanja, je šola življenja.

V opisanem kulturnem turizmu je šlo, danes bi rekli, za srečevanje in bogatenje različnih referenčnih okvirov. Novi vtisi so predelani vstopili v referenčni okvir potnikov. Značilna za kulturni turizem pa sta bila namen in volja kulturnih turistov, da se s potovanja vrnejo obogateni in drugačni. Zato so bila kulturna potovanja natanko načrtovana in nikakor niso mogla biti prepuščena naključju.
Znanje so kulturni turisti pridobivali zvečine pred potovanjem, med njim in po njem. Kulturni turizem tako ni mogel biti in ne more biti le konzumiranje vtisov. Kulturni turizem zahteva dejavno sodelovanje in ne more biti, kot je $\mathrm{v}$ turizmu danes pogosto navada, konzumiranje kulture.

Baretto (2007) opredeljuje kulturni turizem kot turizem, ki ponuja pričevanje o obstoju privlačnih, vrednih in pristnih vidikov življenja neke družbe, kulture, naroda in narodnega izraza. Tako se kulturni turizem nujno povezuje z znanjem in pridobivanjem znanja tako tistih, ki turiste sprejmejo, kakor tudi turistov samih. Še več, s kulturnim turizmom zadovoljujemo hkrati dve neločljivo povezani potrebi: potrebo človeštva po gibanju v prostoru in potrebo po simbolnem izražanju. Zdi se, da se je kulturni turizem oblikoval kot razmeroma pozen odziv na primarno potrebo po gibanju, ki se je rodila zgodaj, saj so bili ljudje v preteklosti prisiljeni z gibanjem in premikanjem $\mathrm{v}$ prostoru iskati hrano (Malinowski, 2001). Da bi razumeli naravo kulturnega turizma, velja najprej proučiti značilnosti sodobne družbe, njene transformacije in vrednote.

\section{ZNAČILNOSTI POSTMODERNE DRUŽBE IN KOMUINIKACIJSKE TEHNOLOGIJE TER NJIHOV VPLIV NA NARAVO SODOBNEGA KULTURNEGA TURIZMA}

Postmoderna družba goji kulturo postmodernih vrednot. V nasprotju z obdobjem moderne priznava in sprejema raznolikost slogov in raznoliko estetiko. Poleg tega je postmoderna čas razstavljanja, čas, ko se rahljajo in fragmentirajo družbene vezi. Pojavi se množica osebnih resnic, saj tehnologija načenja veljavnost doslej priznanih znanstvenih trditev, 
etike in estetike, s tem pa naravnost dramatično spreminja predstavo o svetu.

Lyotard (2003) trdi, da postmoderno zaznamujeta stalno spreminjanje in nenehno iskanje nedosegljivega. Tudi kulturni turizem je izraz tega dejstva. Kulturni turist išče v drugih kulturah spremembo, spoznava nove načine življenja, nove odnose in načine sporazumevanja, želi odkriti in ustvariti novo znanje, se spremeniti, se predrugačiti. K temu pripomore doživljajsko učenje, ki je na potovanjih pogostejše kot $\mathrm{v}$ predavalnici.

Še več, kulturni turizem ne temelji na podatkovnem znanju, temelji predvsem na živih odnosih, izkustvu drugega, na doživljanju v kontekstu. Pri tem se postavi vprašanje, ali je kontekst mogoče dobro pričarati s pomočjo informacijsko-komunikacijskih tehnologij. Informacijsko-komunikacijske tehnologije sicer lahko zbudijo zanimanje kulturnih turistov za odkrivanje tujih kultur in zaradi prebujenega zanimanja so pričakovanja kulturnih turistov večja. Tako kulturni turisti pričakujejo, da jim bo potovanje zagotovilo pristna srečanja $z$ drugimi, z njihovim načinom življenja, njihovo kulturo. Pričakujejo, da bo na poti dovolj doživljajskega učenja, ki ga lahko zagotovijo le $\mathrm{v}$ danem kontekstu vzpostavljeni odnosi in uporaba vseh čutov hkrati.

Današnje informacijsko-komunikacijske tehnologije omogočajo, da smo lahko v slehernem prostoru in ob slehernem času, zato danes drugače kot nekoč potujemo skozi prostor in čas. Tako razdalja ni nič več čarobna in skrivnostna, zaradi informacijsko-komunikacijskih tehnologij je tako rekoč odpravljena. Današnji človek se znajde ob drugem človeku brez razdalje, iz oči v oči, brez pogleda nanj. Če odpravimo čas in če odpravimo prostor, kar se zaradi hitre komunikacije in hitrega transporta dogaja, se spremeni prav vse in tako nas zlagoma zanima le, kar je tu in zdaj. Kulturni turizem pa vrača razdaljo, daje doživetjem turista globino in širino, značilno za kulturo, daje poudarek kontinuiteti. Kulturni turizem ne more biti konzumiranje kulturnih dobrin. Kot smo že dejali, ne more biti tekanje od muzeja do muzeja, od mestne četrti do mestne četrti, od mesta do mesta brez znanja in razdalje, brez pogleda od daleč. Pogleda, za katerega potrebujemo čas, poglabljanje znanja in doživljanje.

Nova tehnologija in novi znanstveni dosežki postmoderne nam dajejo novo mesto na zemlji, saj nam zagotavljajo pogled od zunaj. Zaradi njih smo danes s svetom in časom drugače povezani, kot smo bili nekoč. S svetom nimamo več »zemljepisne povezave«, svet

\section{Kulturni turizem se nujno povezuje z znanjem in pridobivanjem znanja.} nosimo na dlani, kar nam omogočajo slike na zaslonu. V naših očeh se svet lahko pojavi tu in takoj ter se zato zdi zmeraj dosegljiv, a o tem svetu si postavljamo prav malo vprašanj. $\mathrm{Z}$ novo komunikacijsko tehnologijo se je naš odnos do sveta spremenil (Ilharco, 2004: 83), kulturni turizem pa želi spodbuditi drugačen odnos do tujih kultur. Kulturni turizem omogoča, da se prizadeto sprašujemo tudi o svoji lastni kulturi: vrednotah, normah, pričakovanjih, da svoje znanje primerjamo z znanjem drugih. Kulturni turizem je tako kot branje počasna dejavnost, kjer se srečujejo različni svetovi in se medsebojno spreminjajo. Ni mogoče zanikati, da tudi nove komunikacijske tehnologije lahko ustvarjajo odnose, pa vendar tudi za tako ustvarjene odnose potrebujemo čas, trajnejše srečevanje in skupna doživetja.

Nova tehnologija je pokazala tudi končnost našega planeta in sveta, končnost virov, s katerimi razpolagamo (Ilharco, 2004: 58). Današnja družba se spričo tehnološke revolucije, 
osredotočene na informacijsko tehnologijo in komunikacijo, nedvomno oblikuje kot družba svetovnih, a hkrati tudi končnih razsežnosti. To dejstvo vpliva na naravo današnjega kulturnega turizma.

\section{SOODVISNOST SVETOVNE IN LOKALNE KULTURE TER USTVARJANJE VIRTUALNE IDENTITETE}

Na svet vse bolj gledamo kot na proces, kot na pretok blaga in komunikacije, in tudi zaradi tega se ustvarja nova svetovna kultura (Denning, 2001: 357). Informacijska tehnologija in komunikacija $\mathrm{v}$ digitalnem jeziku dajeta današnjemu svetu skupen pomen. Kaj je posledica tega? Ekonomska prevlada ustvarja kulturno prevlado; uveljavijo se zgolj nekateri koncepti. Če pa globalizacijo razumemo kot dinamičen proces in kot zgodovino, globalizacija omogoča tudi rast lokalne kulture in kultur, pri čemer lokalna kultura bodisi posrka uveljavljene standarde bodisi se upre nadvladi globalne kulture (Herscovici, 1996: 62). Tako oblikovana lokalna kultura, lokalna kultura v razmerju do globalne kulture, se pojavlja v kulturnem turizmu.

Današnja informacijska tehnologija in današnje komunikacije delujejo v svetovnih okvirih. Spreminjajo realnost in ji dodajajo tudi naša doživetja. Računalniške mreže ustvarjajo nove in nove komunikacijske kanale, ki nazadnje oblikujejo življenje posameznika in skupnosti. Zaradi tehnoloških možnosti, da se življenje globalizira, se oblikujejo tudi reakcije na globalizacijo, tj. iskanje lastne individualne in skupnostne identitete, na podlagi katere posameznik svetu, ki ga obdaja, pripiše takšen ali drugačen pomen (Castells, 2002). Tako je za udeležene v kulturnem turizmu pomembno, da gradijo svojo osebno in lokalno identiteto, srečujoč se z drugimi identitetami in kulturami.

Sodobni človek pa svojo osebno in skupnostno identiteto ter kulturo ustvarja tudi $\mathrm{v}$ sti$\mathrm{ku} \mathrm{z}$ zaslonom. Gre za virtualno identiteto in kulturo. Na eni strani vemo, da virtualna identiteta ni resnična; obstaja namreč na zaslonu, računalniškem, televizijskem, filmskem ali celo na zaslonu telefona. Na drugi strani pa ta virtualna identiteta pristane nekje v ozadju naše eksistence, kjer izgubi svojo neresničnost in postane del realnosti. Kar je virtualno, postane realno, torej sprejeto, Baudrillard (1991) in Barthes (1997) tako trdita, da sprejetost pomeni, da kultura in komunikacijski procesi začnejo brisati mejo med realnostjo in predstavo o realnosti (Castells, 2002: 488-489). Današnji turist tako potuje s pomočjo zaslona. Svetovni splet virtualno ponuja kulture, muzeje, izkustvo, kulturne izmenjave, ki jih je nekoč lahko omogočilo le fizično potovanje. Se bomo v prihodnosti omejili na virtualna potovanja?

\section{PODROČJA KULTURNEGA TURIZMA}

V devetdesetih letih so zaznali povečanje obiska muzejev in zgodovinskih krajev, kulturna dediščina $\mathrm{v}$ mestih in regijah, ki so bili doslej zapuščeni in pozabljeni, je vir za mnoge ekonomske pobude. Povezava med turizmom in kulturo nedvomno povzroča, da se kulturna dediščina vključuje v evropsko ekonomsko in družbeno dinamiko razvoja.

V kulturnem turizmu je najpomembnejši dejavnik povpraševanja »kulturni kapital « (raven izobrazbe in družinsko izročilo), medtem ko je pri drugih vrstah turizma najpomembnejša cena potovanja. Pri kulturnih turistih cena nima posebne vloge, saj dajejo prednost 
kulturi in znanju. Za te turiste je potovanje priložnost, da na tujem območju, zunaj domačega kraja, nadaljujejo svoje siceršnje kulturne dejavnosti. Potujejo glede na svoje že osvojeno znanje, glede na predhodne reference ali študij. Kulturni turisti največkrat obiščejo mesta, muzeje, zgodovinske kraje. Zanimajo se za tehniško in industrijsko dediščino, spomenike, galerije, obiščejo kakšen festival in se udeležijo praznovanj. Značilna oblika kulturnega turizma je bivanje $\mathrm{v}$ mestu, kajti mesto navadno ponuja vrsto kulturnih doživetij. Le bivanje $v$ mestu lahko zagotovi več kulturnih dogodkov v enem samem dne$\mathrm{vu}$; dopoldanski obisk muzeja, popoldanski ogled spomenikov, sprehode skozi mesto, večerne prireditve. Bivanje v mestu tako ustreza tistim turistom, ki so lačni kulture.

Kulturni turisti obiskujejo sakralne objekte, umetnostne muzeje, arheološka najdišča, gradove, tematske muzeje, spominske kraje, utrdbe, ekomuzeje, znanstvene in tehniške muzeje, naravoslovne muzeje, parke in vrtove, festivale. Posebno pozornost namenjajo kulturnim spomenikom, vpisanim na sezname kulturne dediščine: zgradbam, spomenikom ali posameznim delom zgradbe (stopnice, balkon itd). Gre za kastelno arhitekturo, sakralne objekte (katedrale, cerkve, samostane), vojaško arhitekturo (obzidja, kasarne ...), javno arhitekturo (mestne hiše, sodne palače). Spominski kraji prav tako pritegnejo njihovo pozornost.

Kulturni turisti pa odkrivajo tudi vasi, kjer gre velikokrat za zanimive arhitektonske celote. Denimo za varovane, zaščitene vasi, kjer je pogosto najti mline, pralnice itd. $\mathrm{V}$ nekaterih je mogoče obiskati obrtne tovarnice, $v$ drugih bivališča slikarjev ali pisateljev in obujati spomin na njih. Na podeželju najdemo tudi glavne spominske kraje iz različnih vojn (bojna polja itd.) Tukaj so denimo urejene tematske ceste, kjer so posamezni elementi dediščine med seboj povezani na podlagi neke zgodovinske teme (Origet du Clouzeau, 2007).

\section{IZOBRAŽEVANJE ODRASLIH, VEČANJE KULTURNEGA KAPITALA IN ZANIMANIA ZA KULTURNI TURIZEM}

Vrednost nekega kraja je v njegovem javnem prostoru. Javni prostor je kraj bolj ali manj intenzivne kulturne produkcije vseh vrst, ki temelji na lokalni tradiciji ali na tisti, ki je nastala pod zunanjimi vplivi. Ta kulturna produkcija, ki se nabira skozi stoletja - nemalokrat pa jo je treba z izobraževanjem odraslih prebivalcev šele odkriti - požene korenine in ustvarja identiteto, zaradi katere je posamezen kraj prepoznaven, drugačen od drugih.

Kulturna destinacija je prostor, ki je lahko širok, kot je široka celina, ali ozek, kot je ozek prostor posamezne vasi. Ta prostor pa lahko različno spodbudi domišljijo turistov. Kulturni turizem je torej najbolj odvisen od mentalnega in kulturnega kapitala tistih, ki potujejo, pa tudi od lokalnih zmožnosti in virov, ki jih ima kraj (angl. local capacity). V ta namen izobražujemo tako odrasle turiste kakor tudi tiste, ki podpirajo lokalni razvoj. Kulturne turiste namreč lahko dobro sprejme le kraj, kjer so prebivalci razvili osebno in družbeno identiteto ter identiteto kraja. $\mathrm{V}$ ta namen prebivalci proučujejo različne vidike svoje kulture: zgodovinskega, umetnostnozgodovinskega, sociološkega, etnološkega, urbanističnega, znanstvenega, umetnostnega in druge. Spoznajo se z lokalno književnostjo. Zbirajo pripovedi in pričevanja o svojem kraju in jih objavljajo. Raziskujejo pretekle načine življenja posameznih družin v kraju in spoznanja objavijo. Organizirajo javne prireditve. 
Kulturni turizem je mogoč le tam, kjer obstaja mreža posameznikov, društev, podjetij, ustanov, v katero se ujame kulturni kapital in v kateri se drobci tega kapitala med seboj povežejo v trdno celoto.

\section{SKLEP}

V družbi znanja, v postmodernem obdobju, je kultura gibalo ekonomskega in družbenega razvoja. Kultura ter kulturni kapital posameznikov in kraja sta postala tudi gibalo kulturnega turizma, ki se je sicer razvil po uveljavitvi kapitalizma in z njim pojava prostega časa $\mathrm{v}$ obdobju moderne. $\mathrm{V}$ postmoderni, pod vplivom novih informacijsko-komunikacijskih tehnologij, se odnos posameznika do časa in prostora spreminja, izginjata razdalja do drugega in njegove kulture ter pogled od daleč, ki se zdita nujna za kulturni turizem. Še več, postavlja se vprašanje, kako bo virtualnost vplivala na prihodnji razvoj kulturnega turizma, za katerega je bilo doslej značilno fizično potovanje, pridobivanje znanja, srečevanje s kulturo drugega in doživljanje v fizičnem kontekstu.

Prevod: Dušana Findeisen

\section{LITERATURA}

Barretto, M. (1995). Manual Initiation to the Study of Tourism. Campinas: Papyrus.

Barretto, M. (2007). Culture And Tourism: Contemporary Discussions. Campinas: Papyrus.

Barnett, S. (1997). »New Media, Old Problems - New technology and The Political Process «. European Journal of Communication, 12(2): 193-218.

Barthes, R. (1997). Mythologies. Lizbona: Publishing 70 editions.
Berger, P. (2003). »Religion and Globalization«. V: Globalization, Science, Culture and Religion, Colloquium at the Calouste Gulbenkian Foundation. Lizbona.

Borugman, A. (1999). Holding on to Reality: The Nature of Information at the Turn of the Millennium. Chicago: The University of Chicago Press.

Bourdieu, P.(2004). For a Sociology of Science. Lizbona: Celta.

Castells, M. (2002). The Information Age: Economy, Society, Culture. Lizbona: Calouste Gulbenkian Foundation.

Denning, M. (2001). »Culture Studies in Globalization: An Epoch Process«. European Journal of Cultural Studies, 4(3): 351-64.

Dickerson, P. (1996). »Let Me Tell us Who I Am The Discursive Construction of Identity Viewer «. European Journal of Communication, 11: 57-82.

Elliot, T. S. (1996). Notes for a Definition of Culture. Lizbona: Século.

Ellul, J. (1964). The Technological Society. New York: Vintage Books.

Giddens, Anthony (2000). The World in the Age of Globalization. Lizbona: Presença.

Herscovici, A. (1996). »The Place in the Era of Globalization: Contribution To A Critical Analysis«. Intercom, Brazilian Journal of Communication, 1: 59-66.

Ilharco, F. (2003). Philosophy of Information - An Introduction to How Information Foundation of Action Communication and Decision. Lizbona: Portuguese Catholic University.

Ilharco, F. (2004). The Technological Issues - Essay on the Contemporary Technological Society.

Lizbona: Principia.

Lyotard, J.-F. (2003). The Postmodern Condition. Lizbona: Gradiva.

Malinowski, B. (2001). The Dynamics of Cultural Change, Oxford: Oxford University Press.

Origet du Clouzeau, C. (2007). Le Tourisme Culturel. Pariz: PUF. 